\title{
Pseudo noun incorporation is M-Merger: evidence from Balinese
}

\author{
Theodore Levin*
}

\section{LSA Annual Meeting, Minneapolis, January 2-5, 2014}

1. Introduction. Noun Incorporation, illustrated in (1), has two consequences: (i) the incorporated nominal is realized adjacent to the verb, (ii) the incorporated nominal is licensed without Case (Baker 1988, 1996).

(1) Mapudungun noun incorporation (Baker 2009)
my father seek-PROG-IND.3ss the COLL cow
'My father is looking for the cows.'
a. Ñi chao kintu-le-y ta chi pu waka
b. $\quad \tilde{N}$ i chao kintu-waka-le-y.
my father seek-cow-PROG-IND.3ss
'My father is looking for the cows.

This raises the question of whether Head Movement or the head-head adjacency it creates is responsible for licensing the incorporated nominal. I suggest that Balinese pseudo noun incorporation (PNI) indicates that adjacency alone is responsible for licensing.

Under commonly held analyses, PNI describes scenario distinct from (1) illustrated in (2).

(2) Niuean pseudo noun incorporation (Seiter 1980)
a. Takafaga tuumau nii e ia e tau ika hunt always EMPH ERG he ABS PL fish
'He is always fishing.'
b. takafaga ika tuumau nii a ia
hunt fish always EMPH ABS he
'He is always fishing.'

Though the internal argument in both (1) and (2) surfaces adjacent to the verb in the (P)NI environment without nominal modification, such as plural marking, Niuean PNI, unlike NI, permits adjectives to appear along with the nominal in the incorporated positon. This has been taken to indicate that PNI does not utilize head-movement, but rather a bare NP complement to $\mathrm{V}^{0}$ (Massam 2001). However, more recently Baker (2012) demonstrates that PNI requires verbnominal adjacency, which is not a direct consequence of merely positing a bare $\mathrm{NP}^{1}$.

In this paper, I argue that adjacency alone can license a nominal by demonstrating that properties of Balinese PNI are incompatible with either (covert) Head Movement (Baker 2012) or with a bare NP analysis (Massam 2001) $)^{2}$. The Balinese data are compatible with a scenario in which the nominal head happens to be adjacent to the verb. In this configuration, head-head adjacency licenses the nominal via M(orphological)-Merger (Marantz 1984). Under the proposed analysis, Balinese PNI is a last resort strategy, which vacuously satisfies the Case Filter.

\footnotetext{
${ }^{*}$ I would like to thank Edith Aldridge, Mark Baker, Dianne Massam, David Pesetsky, Norvin Richards and Nyoman Udayana for helpful comments and criticisms. I would also like to that Nyoman Udayana for help with judgments. All errors are my own. Author: Theodore Levin, Massachusetts Institute of Technology (tedlevin@ mit.edu).

${ }^{1}$ Modification of the kind found in Niuean is only permitted if the modifier does not intervene between the nominal and verbal heads, suggesting that covert head movement may be occurring.

${ }^{2}$ I do not mean to deny the possible reality of an NP/DP distinction. I will use the term PNI to refer specifically to constructions which show strict head-head adjacency without affixation.
} 
2. Balinese voice. Balinese exhibits an Indonesian-type voice alternation.

(3) Balinese voice alternation
a. jaran-e gugut cicing horse-DEF OV.bite dog 'A dog bit the horse.'
b. cicing ngugut jaran-e
dog AV.bite horse-DEF
'A dog bit the horse.'

In general, two transitive voices are available. When any internal argument is promoted to the pre-verbal subject position the verb is realized in object voice (3a). When the external argument is promoted to subject, the verb is in agent voice. The preverbal element is the subject regardless of thematic role (Artawa 1994; Wechsler \& Arka 1998).

3. Balinese PNI displays strict head-head adjacency. Like many other Austronesian-type voice systems, Balinese external arguments which are not promoted to subject show idiosyncratic behavior. The verb and nominal head (whether $\mathrm{N}^{0}$ or $\mathrm{D}^{0}$ ) must be linearly adjacent ${ }^{3}$. Whenever linear adjacency is not maintained, ungrammaticality arises.

3.1. NP-EXTERNAL INTERVENTION. No element can intervene between a post-verbal Agent and the verb (Wechlser \& Arka 1998).

(4) Intervention blocks PNI (Wechlser \& Arka 1998: 405)
a. siap-e [v uber] ${ }_{\mathrm{N}}$ cicing] ke jalan-e chicken-DEF OV.chase dog into street-DEF
$S \vee O_{\text {Agent }} P P$
'A dog chased the chicken into the street.'
b. [ [v uber] [N cicing] ke jalan-e siape-e
$\mathrm{V} \mathrm{O}_{\text {Agent }} \mathrm{S}$ PP
c. [v uber] siap-e [N cicing] ke jalan-e
$* V \mathrm{~S} \mathrm{O}_{\text {Agent }} \mathrm{PP}$
d. siap-e [v uber] ke jalan-e [ ${ }_{\mathrm{N}}$ cicing]
$* \mathrm{~S} V \mathrm{PP} \mathrm{O}_{\text {Agent }}$

If another constituent, either an argument (4c) or adjunct (4d), intervenes the string is ungrammatical.

3.2 Wh-MOVEMENT. Subsequent syntactic operations on the external argument also cannot break up verb-nominal adjacency. Post-verbal Themes (5a), but not post-verbal Agents (5b), can undergo $w h$-movement ${ }^{4}$ (Levin 2012).

(5) Wh-movement blocks PNI.
a. [N buku] cen John [v paca]. book which J. OV.read
'Which book did John read?' person small which fish-DEF OV.eat ('Which boy ate the fish?')
b. * [N anak] cerik cen be-e [v daar]

\footnotetext{
${ }^{3}$ Malagasy shows a similar effect (e.g. Pearson 2001).

${ }^{4}$ Interestingly, wh-movement is often uniformly blocked from non-initial position in Austronesian.
} 
The behavior of in situ external arguments in (4) and (5) is expected if adjacency is necessary for licensing. Intervening elements in (4) and movement operations in (5) disrupt this adjacency.

3.3 NP-INTERNAL RIGIDITY. It is conceivable that (4) and (5) show merely that the NP as a whole must be adjacent to the verb (cf. Massam 2001). However, additional evidence shows that it is the head of the nominal phrase that must be adjacent.

While commonly $\mathrm{N}^{0}$-initial within the NP, Balinese permits weak quantifiers (and numerals) to appear to the left of $\mathrm{N}^{0}$ (16a). This ordering is impossible for in situ Agents in OV (16b).

(6) Adjective intervention blocks PNI

a. (liu) [ ${ }_{\mathrm{N}}$ cicing] (liu) [v pugut] Nyoman

(many) dog (many) AV.bite N.

'Many dogs bit Nyoman.'

b. Nyoman [v gugut] (*liu) [ ${ }_{\mathrm{N}}$ cicing] (liu)

N. OV.bite (*many) dog (many)

'Many dogs bit Nyoman.

Intervening adjectives, just like intervening NPs and PPs (3) disrupt verb-Agent adjacency.

Massam's (2001) analysis does not account for NP-internal word order rigidity ${ }^{5}$ : An inert NP should not display any NP-internal word order effects.

3.4 'DEFINITENESS EFFECT'. The definiteness effect in post-verbal Agents, which first led to the (P)NI analysis of Balinese (e.g. Clynes 1995), can also be viewed as an adjacency requirement. (Some) Balinese post-verbal Agents must be indefinite. The definite suffix $-e$ and overt determiners like ento 'that' are illicit.

(7) Definitiness effect (Wechsler \& Arka 1998: 401)

I Wayan [v gugut] [N cicing]/* cicing-e [ ${ }_{\mathrm{D}}$ ento]

ART W. OV.bite dog dog-DEF that

'A/*the dog bit Wayan'

Under commonly held theories of (P)NI, the definiteness effect is attributed to the supposedly obligatory NP status of the nominal. However, Balinese illustrates that DPs can also participate in the construction, so long as $\mathrm{D}^{\circ}$ is adjacent to $\mathrm{V}$.

(8) $\mathrm{D}^{0}$-Incorporation

a. be-e [ ${ }_{\mathrm{v}}$ daar] ${ }_{\mathrm{D}}$ ida]
fish-DEF OV.eat $3 \mathrm{~s}$
'(S)he ate the fish.'

b. be-e [vdaar] [D Nyoman]

be-DEF OV.eat $\mathrm{N}$.

'Nyoman ate the fish.'

(9) Intervention blocks $\mathrm{D}^{0}$-Incorporation

* be-e [v daar] keras-keras [D ida]/ [D Nyoman]

fish-DEF OV.eat quickly $3 \mathrm{~s} / \mathrm{N}$.

('She/Nyoman ate the fish quickly.')

\footnotetext{
${ }^{5}$ Baker (2012), citing Chung \& Ladusaw (2004), makes the same point using data from Chamorro. In which relative clauses show linear freedom with respect to head nouns except in incorporation environments.
} 
Pronouns and proper names are unique amongst definite DPs in lacking (overt) intervening NP material. Pronouns occupy $\mathrm{D}^{0}$ and lack a NP complement (e.g Postal 1966, Elbourne 2001). Proper names, in Balinese, may move to $\mathrm{D}^{0}$ (cf. Longobardi 1994).

4. Morphological-merger. Section 3 illustrates that nominal heads of post-verbal Agents must appear immediately to the right of the verb. This scenario also characterizes true noun incorporation (1) and pseudo noun incorporation (2). However, further examination of the phenomenon reveals that Balinese PNI is problematic for previous accounts: (i) PNI is licensed from Spec-vP, which is unexpected on a covert head movement account (Baker 1988). (ii) Balinese PNI displays NP-internal word order effects, which is unexpected if PNI is just merger of an NP rather than a DP (Massam 2001). (iii) $\mathrm{D}^{0}$ s can undergo PNI, which is unexpected if only $\mathrm{N}^{0}$ /NP undergo PNI (Baker 2012, Massam 2001). (iv) Balinese PNI is sensitive to intervention from structurally lower elements indicating that linear adjacency is relevant. Instead, I suggest that at PF, M-Merger, diagramed in (10), applies licensing the postverbal Agent.

$$
\begin{aligned}
& \text { Morphological Merger (Marantz 1984) } \\
& \mathrm{V}^{0}\left[\mathrm{HP}^{0}\right] \rightarrow\left[\mathrm{V}^{0}+\mathrm{N}^{0}\right]
\end{aligned}
$$

M-Merger exchanges the immediate c-command relation between $\mathrm{T}^{0}$ and Spec- $v \mathrm{P}$ for a linear adjunction relationship. Support for this analysis comes from the observation that the verb and post-verbal Agent are treated as a single phonological word (Clynes 1995). The adjacency requirement holds because (10) can only apply when the verbal and nominal elements are linearly adjacent. Intervention of any kind disrupts adjacency, blocking M-Merger and yielding a derivation which violates the (late) Case Filter.

\section{References}

Artawa, Ketut. 1994. Ergativity and Balinese syntax. Bundoora, Australia: La Trobe University dissertation.

Baker, Mark C. 1988. Incorporation: a theory of grammatical function changing. Chicago: University of Chicago Press.

Baker, Mark C. 2009. Is head movement still needed for incorporation: the case of Mapudungun. Lingua 119. 14865.

Baker, Mark C. 2012. Pseudo-noun incorporation as covert noun incorporation: linearization and crosslinguistic variation. New Brunswick, NJ: Rutgers University manuscript.

Baker, Mark C. \& Kenneth Hale. 1990. Relativized minimality and pronoun incorporation. Linguistic Inquiry 21. 289-97.

Chung, Sandra \& William A. Ladusaw. 2004. Restriction and saturation. Cambridge, MA: MIT Press.

Clynes, Adrian. 1995. Topics in the phonology and morphosyntax of Balinese - based on the dialect of Singaraja, North Bali. Canberra, Australia: Australia National University dissertation.

Elbourne, Paul. 2001. E-type anaphora as NP-deletion. Natural Language Semantics 9. 241-88.

Longobardi. Giuseppe. 1994. Reference and proper names. Linguistic Inquiry 25. 609-65.

Marantz, Alec. 1984. On the nature of grammatical relations. Cambridge, MA: MIT Press.

Massam, Dianne. 2001. Pseudo noun incorporation in Niuean. Natural Language and Linguistic Theory 19. $75-134$.

Pearson, Matthew. 2001. The clause structure of Malagasy: a minimalist approach. Los Angeles: UCLA dissertation.

Postal, Paul. 1966. On so-called 'pronouns' in English. In F. Dinneen (ed.), 19th Monograph on Languages and Linguistics. Washington, DC: Georgetown University Press.

Wechsler, Stephen \& I Wayan Arka. 1998. Syntactic ergativity in Balinese: an argument structure based theory. Natural Language and Linguistic Theory 16. 387-441. 